\title{
Disturbing Lessons from Free Primary Education in Sub Saharan African: A Case of Kenya, Tanzania, Malawi \& Mozambique
}

\author{
Lucy Njura Barimbui Njeru \\ Catholic University of Eastern Africa, Nairobi, Kenya
}

\section{Email address:}

lucynjura@gmail.com

\section{To cite this article:}

Lucy Njura Barimbui Njeru. Disturbing Lessons from Free Primary Education in Sub Saharan African: A Case of Kenya, Tanzania, Malawi \& Mozambique. Education Journal. Vol. 8, No. 1, 2019, pp. 30-35. doi: 10.11648/j.edu.20190801.15

Received: January 20, 2019; Accepted: February 25, 2019; Published: March 18, 2019

\begin{abstract}
A study on the progress of free primary education in Kenya, Tanzania, Malawi and Mozambique was conducted via literature search. A critical analysis of statistics from local and international websites was done with the aim of assessing the progress of free primary education in Sub Saharan Africa. Several conclusions were made about the progress of free primary education in Sub Saharan Africa. The first observation was that, there has been a steady progress in education in relation to the out of primary school rates as well as dropout over the past three decades. The African governments failed to eradicate the out of primary school children's exorbitant numbers since 1990. As at 1990, 38.8 million primary aged students were out of schools in Sub Saharan Africa. The figure dropped to 34.1 million as of 2016. The second observation was that the African governments have been reluctant to set the actual cost of primary education per student per year. An average cost of less than $\$ 14$ per primary student per year paid as grant by the Sub Saharan governments is insufficient to promote quality. Finally, whereas education has been perceived to be a vehicle of dealing with inequality, free primary education was observed to be fueling inequality among the students within, between countries and globally. Therefore, African governments should set strong monitoring and evaluation departments with the aim of eradicating challenges of free primary education. The problems of teacher-students ratio, dropout and out of primary school children has been there three decades ago and even today. A strong monitoring and evaluation systems could have eliminated these challenges in 1990s.
\end{abstract}

Keywords: Free Primary Education, Cost of Education, Education Inequality, Education for All, Out of Primary Education

\section{Introduction}

Free primary education was introduced more than hundred years ago by most of the developed nations. An excellent progress in the funding of primary education was reported in countries like France, Australia, New Zealand, United Kingdom, Canada, United States and others. Sweden is being credited for introducing free education at all levels of learning. The developed world is always taking education as a basic human right. Asia has been slow in funding education but is catching up with the developed world. Funding of Free education beyond primary level is on increase in the Asian world and a lot of progress has been reported. Africa is still struggling to adequately fund primary education. The progress of education funding can be classified as satisfactory. The purpose of this article is to expose gaps that still exist in free primary education funding in Africa with the aim of improving education's external and internal efficiencies. They say statistics do not lie, the study made a quantitative comparison of free primary education progress in Sub Saharan Africa and at global level. However, some qualitative analysis was also done based on the critical examination of empirical literature.

Origin of Free Primary Education in Tanzania, Malawi, Kenya \& Mozambique

The realization that education is important for development came late in Africa. In the western world, free education from primary through to secondary was introduced more than hundred years ago. Malawi was among the first African countries to introduce free primary education [1]. Malawi established free primary education in October 1994. The Kamuzu Banda government had a kind of cost sharing 
formula with parents/guardians in funding primary school education. The move to introduce free primary education in October 1994 was resisted by civic groups raising quality education concerns. However, the government moved on with the policy despite a strong resistance from civic groups.

I strongly support the government of Malawi for imposing free primary education despite the outcry from the civic society. Imposing free primary education in Malawi and other African nations was a necessary evil, it is immoral for young and innocent kids to stay out of school because parents cannot afford to pay for their tuition fees. The social demand approach to education planning was therefore necessary for the under privileged children to find themselves in schools. The education quality concerns were raised by the World Bank and UNICEF report of 2009 [1]. The introduction of free primary education worsened the quality of education and the time has come for African nations to close the gaps and improve the quality of primary education.

Tanzania introduced its free primary education in 2001 through the launch of Education Development Plan (PEDP). The aim of the PEDP was to wave tuition at primary level, expand enrolment and improve teaching and learning among other factors. The initial step was for Tanzania to impose free tuition for 7-10 year olds but was later extended. The mandatory cash contributions charged by the schools were abolished and uniforms were not compulsory. A bursary of $\$ 10$ was introduced per student [1].

The free primary education of Malawi had similar experiences to those of Tanzania, uniforms were not mandatory like in Kenya. It was the responsibility of the parents to pay for the cost of uniforms and the examination fees. According to the National Committee on Educational Objectives (NCEO) report of 1975, the introduction of hidden costs like school informs and levy fees increased dropout rates in primary schools in Kenya [2]. A lot of questions have been raised on the definition of free primary education in Africa in sections of this paper. What is called free education in Africa may not be free education in other continents.

The credit for free education in Kenya has been given to Kibaki government who introduced free education in January 2003. However, literature has shown that free education in Kenya started in 1974 under the KANU government. According to NCEO report, FPE started as abolition of tuition for students in standards 1-4 in 1974. The NCEO report of 1975 recommended that the abolition could be extended to standards 5-7 a move that government implemented in 1977 [2]. The free primary education in Kenya was introduced abruptly without proper planning and funding. Just like in Malawi, Tanzania and Mozambique, the quality of primary education in Kenya was compromised by the introduction of free education policy [3].

According to Mozambique's ministry of education, the free primary education in Mozambique has been in existence since 1994 [4]. The most interesting thing to note is that, education in Mozambique is a basic right, compulsory and is enshrined in the constitution of the country. The constitution that declared education a right was enacted in November 1990 [5]. Technically, free primary education in Mozambique could have been introduced in November 1990 as per article 88 of the constitution. This will make Mozambique to be among the first countries to introduce free primary education in Sub Saharan Africa including Malawi.

\section{Methods}

The study was based on literature search. Statistics from local and international websites were used to assess the progress of free primary education in Sub Saharan Africa. Empirical literature on free primary education in Sub Saharan Africa and beyond were also used to assess the progress of free primary education. Quantitative and qualitative approaches were used during the analysis.

\section{Results \& Discussion}

\subsection{Cost of Free Primary Education in Tanzania, Kenya, Malawi \& Mozambique}

African countries spend much of their annual budgets on funding education but the cost of education is incredible to grasp. It is quite shocking to note that some Sub Saharan countries are still paying less than $\$ 1$ as a grant per year per student in primary schools. In United Kingdom a total cost of a primary student is estimated at $£ 4,000$. The government awards grants that vary from $£ 4,000-£ 7,000$ per year per student from the ages of 3-18 years. In United States of America, the estimated cost of primary education per student per year is $\$ 7,750$ a region that is similar to the levels of grants provided by the government of UK. In Africa where quite a number of families are surviving on less than $\$ 1$ per day, some of the Sub Saharan governments are paying a grant of less than $\$ 1$ per student per year as part of free primary education expenditure [5].

In Tanzania, the annual cost of primary education paid by government as grant is estimated at $\$ 10$ per student [6]. The primary education in Tanzania is divided into three categories. There are public schools that are owned by the government, their medium of instruction is Kisiwahili. The second category is classified as English medium primary schools, they follow the country's national curriculum but learn in English. The final category is that of international schools. They study international (western) curricula and the media of instruction is English. Questions were raised on the media of instruction in Tanzania. Why are other students learning in Kisiwahili while others are learning in English? Is this not segregation or education inequality?

The top 10 most expensive schools in Tanzania are all international schools charging school fees ranging from $\$ 5,000-\$ 28,250$. The International School of Tanganyika (IST) was leading the group. The average cost of primary English medium schools in Tanzania is $\$ 500$ per year [7]. This is the scenario in Tanzania where students in public schools are being awarded with a grant of $\$ 10$ per year per 
student. Interesting to note here is that, some schools in Tanzania are charging school fees more than the grants offered by the USA and UK governments per student. On the other hand, public primary school students are awarded a grant of $\$ 10$ per annum less than the cost of transport by bus (one way) from Dar er salaam to Mbeya city.

Kenya is considered to be the powerhouse of East Africa and is leading in terms of primary education funding. It is among the top countries that have bigger budgets in education. The cost of grant for free primary education in Kenya was almost $\$ 10$ per year in 2011 [8]. Ngware claimed that the cost had since shifted to $\$ 14$ per student per year [9]. The World Bank report of 2009 in collaboration with UNICEF claimed that Kenya was leading Tanzania, Zambia, Uganda, Malawi and Mozambique in terms of funding free primary education per student [5].

Just like in Tanzania, the cost of top 10 private international schools in Kenya is alarming. According to a survey done by Ngina [10], the school fees charged by five selected international schools ranged from \$13,000-\$29,000 per year per student. The international school of Kenya was leading, charging tuition fees of $\$ 15,000-\$ 29,000$ from Kindergarten to grade 12 per year, bus fare of $\$ 1,900$ and admission fees of $\$ 400$. Just like in Tanzania, some schools in Kenya charge higher school fees than public schools in United Kingdom and United States of America. Even if we are to compare the bus fare ( $\$ 400$ charged per term) by International School of Kenya and the grant (\$14) paid by the government per year per student, the conclusion is still incredible. The formula to compute the cost of free primary education by the African governments should be scrutinized. The difference between the fees charged by the government schools and private primary schools is too huge. Which figure should be trusted, that of the private or public schools?

According to the World Bank report in collaboration with UNICEF of 2009, Malawi and Mozambique were trailing Kenya in terms of funding [5]. It is true that, the two countries are charging less than $\$ 14$ per student per year. The private international schools of Mozambique are charging an average of $\$ 2200$ per year. The private schools using Mozambique curriculum are charging \$700-\$925. American International School of Mozambique was leading in terms of the cost. The same applies to Malawi international schools, the average charge per year per student is at $\$ 10,000$ [4]. This is the scenarios that we have in Kenya, Tanzania, Malawi and Mozambique. This raises the question on the education purchasing differences between public and private. Of concern is possible differences in provision of learning materials, infrastructure and the impact on learning processes. The consequence will be in the final outcomes.

\subsection{Controversy of Free Primary Education in Africa}

Basing on the statistics of free primary education in Kenya, Tanzania, Malawi and Mozambique, a conclusion can be made that what Africa is calling free education is not free education. A charge of less than $\$ 15$ per student charged by the bulky of African countries is an insult to quality education. In USA and UK, the cost per student is at $\$ 7,750$ and $£ 4,000$ per student respectively. In Kenya, international schools are charging $\$ 13,000-\$ 29,000$ per student, $\$ 700$ $\$ 950$ for Mozambique private primary schools studying Mozambique's national curriculum and an average of $\$ 500$ per year for primary English medium schools following the Tanzanian curriculum.

For primary students studying the same curriculum, some are given a grant of less than $\$ 15$ while others are charged at $\$ 700-\$ 950$ (Malawi) and average of $\$ 500$ in Tanzania. The difference is unacceptable given that the students are studying the same kind of curriculum. The cost of bus fare per term per student for private schools is far higher than the grant contributed by African governments per student in public schools. One cost should be misleading between the cost of the private and government schools. There is no doubt that the African governments are suppressing the actual cost of primary education in Africa. I strongly believe that the cost of private primary schools following the government curriculum is closer to the reality about the actual cost of primary education in Africa though it is still below the expected level. The cost of education in Africa should be determined by an independent body. The governments should accept the reality rather than imposing the figure without putting the necessary costs of primary education into considerations; a fact that could adversely affect quality.

The teachers in Africa are the lowest paid throughout the globe because of the suppression of the cost of education in Africa. The African governments have not been fair in charging the actual cost of education since independence. Free education was introduced in Kenya (2003), Tanzania (2001), Malawi (1994) and Mozambique (1990/1994). However, there has been insignificant improvement in determining the actual cost of free primary education. A lot of complaints on the quality of education has been raised in Africa and the problems are caused by the wrong estimation of the actual cost of primary education. If the problem of the cost is solved, the challenges of the quality of education in Africa will be corrected. There are four things that the African governments should do in order to face head on the challenges of free primary education in Africa;

1. Accept that what they are calling free education is not free education

2. Appoint an independent body to determine the actual cost of education at all levels

3. Subsidize cost at any level basing on their capacities

4. Compete with private sector in education provision and quality

Therefore, what is called free primary education in Sub Saharan Africa is a subsidized cost that is not at par with the actual cost of primary education. There is high politicization of education in Africa, however, the actual cost of education in Sub Saharan Africa should be known before funding of primary school students by the governments. This will help governments to eliminate challenges of free primary education. 


\subsection{Access of Free Primary Education in Sub Saharan Africa}

There is no evidence that African governments are taking serious steps to solve problems related to the number of out of school children at primary, dropouts and enrolment. Statistical data from 1990 according to UNESCO institute of statistics [14] has shown worrying trends;

1. Out of the 63.3 million primary school aged children out of schools globally, more $50 \%$ are from Sub Saharan Africa

2. Out of the 34.1 million primary school aged children out of schools in Sub Saharan Africa, more 50\% are from war tone countries

3. Out of the 34.1 million primary school aged children out of schools in Sub Saharan Africa, 53\% are innocent girls. At least 18,073,000 primary school aged children out of school are girl children

4. The average dropout at primary school level is above $30 \%$ in Sub Saharan Africa

Since 1990s, African leaders should have taken necessary steps to solve the education problems in Africa. It seems as if their monitoring and evaluation programs have not been effective. An effective continent does not need three decades to solve the problems related to out of school children, dropouts and enrolment. According to the latest data on Sweden's education, the dropout rate of Sweden has been less than 0.32 per 1000 students who joined primary school. The number of dropout was $1.3 \%$ in 2000 , reduced to $0.4 \%$ in $2007,0.32 \%$ in 2011 and has been less than $0.32 \%$ at present [12]. In comparison with Kenya, the dropout rate has been ranging between $27 \%-32 \%$ of primary school dropout between 2003 and 2015. There is a clear indication that Sweden has been able to monitor, evaluate and correct their short falls since 2000 a case which was not the same with Kenya. It is still shocking in this age to have Sub Saharan countries having such shocking statistics on primary school dropout. It is obvious that proper solutions were not put in place to monitor the development and progress of education in Africa.

This section depends on the latest data from UNESCO [11] and KNOEMA [13]. Statistical data do not lie. According to the UNESCO Institute of Statistics [14], the global distribution of out of primary school children by country's income levels were as follows by 2016 ;

1. Low income countries 21.9 million

2. Lower middle income countries 31.0 million

3. Upper middle income countries 7.9 million

4. High income countries 2.6 million

5. Total of 63.3 million children out of school globally

Out of the total of 63.3 million children out of primary school globally, 34.1 million were in Sub Saharan Africa by 2016. In 2014 the number was at 34.2 million, 29.6 million (2012), 40 million (2000) and 38.8 million (1990). In comparison of Sub Saharan Africa with other parts of the world, Southern Asia had 10.3 million out of primary school children in 2016, Eastern and Southern Asia (7.2 million),
North Africa and Western Asia (5.8 million), Europe and North America (2.5 million) and Oceania ( 0.3 million). This is the latest development in terms of children out of school globally and the news in Sub Saharan Africa and Asia is not pleasing [14].

What is also disheartening to note is that, the progress of out of primary school children in Sub Saharan Africa has not been improving. In 1990, the number of out of primary school children was at 38.8 million and 34.1 million in 2016. For more than three decades, Sub Saharan African countries failed to reduce out of primary school children by more than $8 \%$. I would have expected the number to have been reduced by more than $70 \%$. The implication is that, Sub Saharan African countries did not manage to improve their monitoring and evaluation departments to strengthen education. It is embarrassing for Africa, there has been minimum if not insignificant progress in terms of the out of primary school rates in Sub Saharan Africa.

The same situation applies to the primary school dropout rates in Africa South of Sahara. The average dropout rate is still at above $30 \%$. What it means is that, of all the primary students who join standard/grade one, more than $30 \%$ of them won't be able to write the final national primary school examinations. The figures in Mozambique are alarming and a drastic action is needed in order to alleviate the situation. The other shocking news according to KNOEMA [13] is that, $11 \%$ of the students who join standard/grade one always fail to complete it in Malawi. It is very disturbing to get such a significant rate at lower levels of primary.

In regards to the out of primary school children, a conclusion is made that Sub Saharan Africa's progress has been insignificant since 1990s. There is evidence that, the monitoring and evaluation departments have not been effective. A lot of effort should have been put in the last three decades, the progress has been insignificant. It is still shocking to grasp that, more than 30 million innocent children in Sub Saharan Africa are out of school. The political leaders in Africa should claim the responsibility and they have to strengthen their monitoring and evaluation skills. They should set annual and long term targets in order for them to solve the challenge of out of primary school children.

\subsection{Equality in Free Primary Education in Sub Saharan Africa}

Key to the observation of this study was the view that equality in primary education is a pipe dream. Whereas an assumption has been that the role of education is to reduce inequality among the students, study's findings observed the opposite. The general agreement by the statistics was that serious inequalities exist among the primary education students. There are some primary students who are better than others and some children within the primary school age have failed to study completely. This section therefore discuss how free primary education has been used by politicians in Sub Saharan Africa to be a vehicle of inequality. 
The study observed that the governments have been encouraging inequality through free primary education by;

1. Under charging, an average cost of less than $\$ 15$ per year per student is insufficient to promote acceptable quality education in Africa. The cost of education in United Kingdom ranges from $£ 4000$ and an average of $\$ 7750$ in United States of America. At times parents opt to take their children to expensive schools even when they are struggling to afford in pursuit of quality.

2. The government sponsored primary schools have been under-resourced to an extent that they cannot compete with private and international schools. The teacherstudents ratio is too high for primary schools owned by the government with 1:73 ratio being reported in Mozambique primary schools. What is shocking to note is that, the ratio failed to improve within the last three decades. The improvement has not been satisfactory.

3. Inequality in primary schools have been enhanced by the governments that discourage parents from contributing to the development of primary schools. In Tanzania and Kenya, the governments do not allow parents to contribute extra fees to the one gazetted by the ministry of education and it is a crime for primary head teachers to request for additional support from parents.

4. The African governments have promoted inequality in primary education by refusing to gazette the actual cost per year of a primary student. It has been difficult to know the actual cost of education at primary level per student and at the same time difficult to accept that a cost of $\$ 14$ per year per student can be enough to carter for lunch of one student per year.

Serious inequalities were observed within and between countries and at global level. The observation that some students in Tanzania are using Kiswahili as a medium of instruction while others are using English is a clear sign of inequality that can be easily avoided. There is a sense that, students from English medium are superior to those in Kisiwahili medium because English is always perceived to be a superior language.

The bus fare paid by a single student in private primary schools per term can pay for more than ten students in government primary schools. Whereas the government primary schools in Kenya are receiving a bursary of $\$ 14$ per year per student, the students in primary private schools using the government curriculum are paying tuition of above $\$ 500$ per year. The international schools are paying an average of $\$ 10,000$ per year. In Tanzania, whereas the government primary schools are paying $\$ 10$ per year per student, the primary English medium schools are charging fees in access of $\$ 500$ per year while international schools are charging $\$ 5,000$ - $\$ 29,000$. The same applies to Malawi and Mozambique, serious inequalities based on fees are in existence.

The other inequality has been observed on the nature of examination, the government schools are making use of the local examination boards while students from international schools are treated with international (American and European) examination boards. I believe that the inequality based on examination boards can be avoided and encouragement is extended for further research by scholars to check on the perception of government primary school students towards international examination boards and vice versa. There is need to find out if public primary students and public in general are comfortable with such disparities in exams.

\section{Conclusion}

Basing on the statistical data from several websites, three key conclusions were made. The first observation was that there has been a steady progress in education in relation to out of primary school children's rates and dropout over the past three decades. The African governments failed to eradicate out of primary school children's exorbitant numbers since 1990. At 1990 the out of primary school number was at 38.8 million as compared to the latest figure of 34.1 of 2016 . The progress has not been satisfactory for the past three decades. Secondly, the African governments have been reluctant to set the actual cost of primary education per student per year. A cost of less than $\$ 15$ is insufficient to promote quality and acceptable education at primary level. Finally, whereas education has been perceived to be a vehicle to deal with inequality problem, free primary education was observed to be fueling inequality among the students within, between countries and globally. Therefore, African governments should set strong monitoring and evaluation departments with the aim of eradicating challenges of free primary education. The problems of teacher-students ratio, dropout and out of primary school children has been there three decades ago and even today. A strong monitoring and evaluation systems could have eliminated these challenges in 1990s.

\section{Abbreviations}

$\begin{array}{ll}\text { FPE } & \text { Free Primary Education } \\ \text { EFA } & \text { Education For All } \\ \text { SSA } & \text { Sub Saharan Africa } \\ \text { PEDP } & \text { Primary Education Development Plan } \\ \text { NCEO } & \text { National Committee on Educational Objectives }\end{array}$

\section{References}

[1] Riddell, A. (2003). Introduction of Free Primary Education in Sub Sahara Africa. https://unesco.org/ark:/48223/pf0000146914

[2] NCEOP, Kenya Education Report (1975). $\mathrm{http} / /$ kenyalaw.org/kl/fileadmin/CommissionReports/Reportof-the-National-Committee-on-Educational-Objectives-1975to-1976.pdf 
[3] Mlinya, L. C. and Orodho, J. A. (2015). Free Primary Education Policy: Coping Strategies in Public Primary Schools in Kakamega South District, Kakamega County, Kenya. Journal of Education and Practice, Vol. 6 (12).

[4] UNESCO, Global Education Monitoring Report 2016. http://unesdoc.unesco.org/images/0024/002457/245752e.pdf

[5] World Bank and UNICEF (2009). Abolishing School Fees in Africa Lessons from Ethiopia, Ghana, Kenya, Malawi, and Mozambique.

[6] Linsojo, K. (2018). The Financial Burden of a Tanzania Free Primary Education on Rural livelihoods: A Case Study from Rural Iringa Region, Tanzania. Development Studies Research, vol. 5 (1).

[7] Tanzania Citizen Newspaper of 15 June 2017.

[8] Ngwacho, G. A. (2011). The Hidden Costs of Free Primary Education and their Implication on Enrolment in Kisii Central District, Kenya. Master of Education Thesis, Kenyatta University.
[9] Orodho, A. J. (2014). Policies on free primary and secondary education in East Africa: Are Kenya and Tanzania on course to attain Education for All (EFA) Goals by 2015? International Organization of Scientific Research (IOSR) Journal of Humanities and Social Sciences (IOSR-JHSS). Vol. 19 (I), 1120 .

[10] Ngina, F. (2018). Top Ten Most Expensive International Schools in Kenya. Standard Newspaper, 05 February 2018.

[11] UNESCO, Education for All Global Monitoring Report 2015. http://unesdoc.unesco.org/images/0023/002322/232205e.pdf

[12] NationMaster, Data on Education Progress in Sweden https://www.nationmaster.com/countryinfo/profiles/Sweden/Education

[13] KNOEMA World Education Statistics https://knoema.com/WBEDS2017Jun/education-statistics

[14] UNESCO Institute of Statistics http://data.uis.unesco.org/Index.aspx?DataSetCode=edulit_ds 